\title{
GREEN SPACE LAYOUT OPTIMIZATION BASED ON MICROCLIMATE ENVIRONMENT FEATURES
}

\author{
GUI QIN WANG ${ }^{1, *}$, BO HONG ZHENG ${ }^{2}$, HANWU YU $^{1} \&$ XIAOGUANG PENG ${ }^{1}$ \\ ${ }^{1}$ School of Architecture and Art Design, Hunan University of Science and Technology, Xiangtan 410000, China. \\ ${ }^{2}$ School of Architecture and Art, Central South University, Changsha 410075, China.
}

\begin{abstract}
Based on the influencing factors of surface roughness, digital terrain, and climate data, determine the city ventilation path and formulate the corresponding guidelines to promote wind circulation. At the same time, by using the numerical simulation method of GIS-CFD, simulating climate environment of the green land layout, The research first comparative analyses the difference of thermal environment with or without green space layout, and further put forward the thermal environment optimization scheme based on urban ventilation path and urban green space ventilation corridor, feedback verification by CFD, find that the urban thermal environment continued to improve. It is beneficial to put forward a practical and operable green space optimization scheme to improve the urban thermal environment from the large scale of the city and the region CFD model, and related research in this paper provide new ideas for urban green space planning and sustainable development.

Keywords: computational fluid dynamics, green space planning, microclimate environment, ventilation paths.
\end{abstract}

\section{INTRODUCTION}

With the acceleration of urbanization, many cities are plagued by fog and haze, and ventilation corridors play an important role in improving microclimate environment [1]. Urban green space is an important component of urban ecological system, which can cool down, increase humidity and improve the ecological environment [2]. Urban ventilation corridors should be assigned with urban green space system as much as possible, the large green spaces should be created or retained on the dominant wind as the city vents, the coupling effect of urban green space system and wind can effectively improve the urban micro climate environment. At present, many scholars have begun to study the micro climate and environment effect of city green space from different angles [3-6].

These studies are mainly divided into three classes: about the improvement of urban thermal environment based on Remote Sensing Technology; about the relationship between vegetation index and urban microclimate environment; about thermal environment effect of urban green space based on ventilation corridors. Taking into account the existing research results, there are mainly three shortcomings: one is the lack of appropriate technical tools to provide a simple and accurate method, and to deepen the study of the relationship between landscape structure and function; two is the little comprehensive application of city climate and landscape ecology principle, establishing and optimizing the effective green space network planning, and simulating the planning scheme; three is seldom taking into account the extreme cases, and studying the case deeply.

The climate environment of our research focuses on wind environment and temperature filed. Our study first determines the urban ventilation path on the basis of topography, building density and building height; through the simulation of the thermal environment with and without the space layout of the green space, next analyzes the relationship between climate environment and green space layout, further establish the reciprocal relationship between the potential pattern of urban thermal environment ventilation and the layout of urban green 
space, establish ventilation corridor systems based on ventilation path. On these bases, several schemes are designed; through feedback verification using FLUENT simulation, the overall planning and design method, which is beneficial to the optimization of urban thermal environment is summarized in order to improve the maximum urban thermal environment.

\section{DATA AND METHOD}

\subsection{Study area}

Hengyang county, located in Hunan province in the Central South of China, is selected as the survey region of our research. Hengyang has a subtropical monsoon climate. According to the statistics of the Municipal Meteorological Observatory: 2010-2014 years, the average temperature is $4.6^{\circ} \mathrm{C}$ in January, the average temperature in July is $29.3^{\circ} \mathrm{C}$, the annual average temperature in the city is $18.5-20.2^{\circ} \mathrm{C}$, and the annual average sunshine coefficient is $1484.7-$ 1723.1 hours. The highest temperature of the year is July. The North wind prevails in winter and the south wind prevails in summer, and the northeast wind with an average speed of $2 \mathrm{~m} / \mathrm{s}$ and a maximum speed of $18.7 \mathrm{~m} / \mathrm{s}$ prevails along the whole year. The green spaces cover an area of $579.97 \mathrm{hm}^{2}$, and the per capita area of parks is $8.34 \mathrm{~m}^{2}$.

\subsection{Data collection}

A QuickBird image in 2015 and Hengyang County Master Plan (2006-2020) (revised in 2013) were used to produce urban land use green space map collected from the Special Plan of Hengyang Country Greenbelt System (revised in 2014), building density through manual interpretation based on GIS and ground truthing methods. The topographic map (1:1000) from 2015 was used to rectify the image. Meteorological data were collected from Hengyang Meteorological Station from 2010 to 2015. This test is mainly to observation, setting the recorder in the test area, recording air temperature, humidity, globe temperature hourly. The instrument consists of HOBO temperature and humidity instrument, JTR series handheld tester (globe temperature tester and wet temperature tester) and type QDF-6 hot bulb anemometer. Field measurements of temperature and wind speed were conducted on 26st May, 2016 with a total of 30 measurement points. Measurement points 1-10 were in the residential area, points 11-20 were in the green spaces, and points 20-30 were on urban roads.

\subsection{Ventilation path}

Ventilation path is a region with low aerodynamics, low roughness and low airflow resistance. The formation of air ducts is based on the ground surface roughness, built height and built density. This study is based on the topographic map of 1:1000 in Hengyang County, and analyze the slope aspect and elevation with ArcGIS, after identified by the main morphological units and separated by absolute values, the peaks are almost all ventilated areas, Hengyang County terrain is high in the North, but low in the South, when the frequent wind along the guiding path through the low-lying areas of the Yuan River Basin, these areas can easily become a good air channel.

Building height and building density data are obtained mainly based on satellite images and actual investigations. Building density was divided into four main groups (Huang, $\mathrm{H}$. et al.[7], [8]) (1) very high density, where buildings occupy approximately $46 \%$ of the total 
area; (2) high density, where buildings cover between $30 \%$ and $45 \%$ of the total area; (3) medium density, where buildings cover between $10 \%$ and $30 \%$ of the total area; (4) low density, which are areas that mostly comprise green space (Fig. 1).

\subsection{CFD Simulation}

\subsubsection{Digitalization of urban geometry}

In this study, firstly simplify model of action in central urban level. On the premise that there is no influence on the general direction of the air flow, taking the main and secondary roads as the boundary, neglect some branches in the county town. Considering the factors such as building height and building density, some plots were merged into a whole. The model of the central urban area is integrated (Fig. 2). At the regional scale, a large number of research results show that: building elements, road corridors and green open space play an important

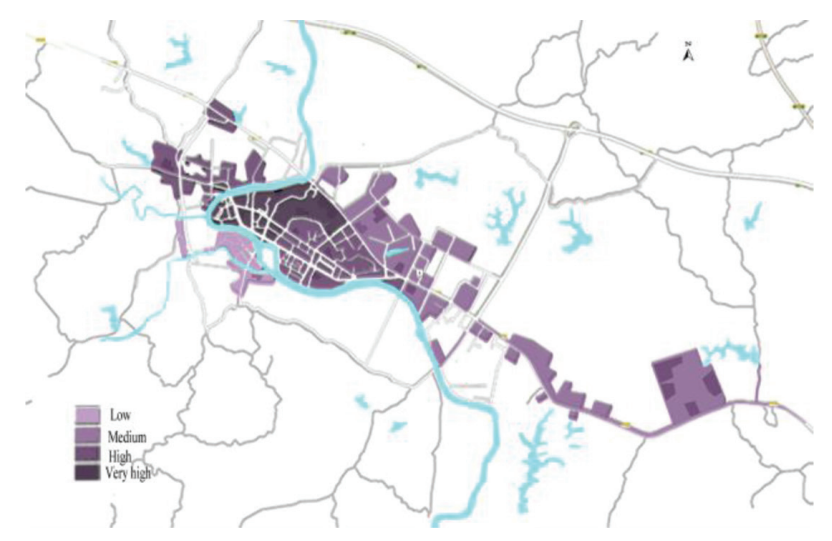

Figure 1: Building density map.

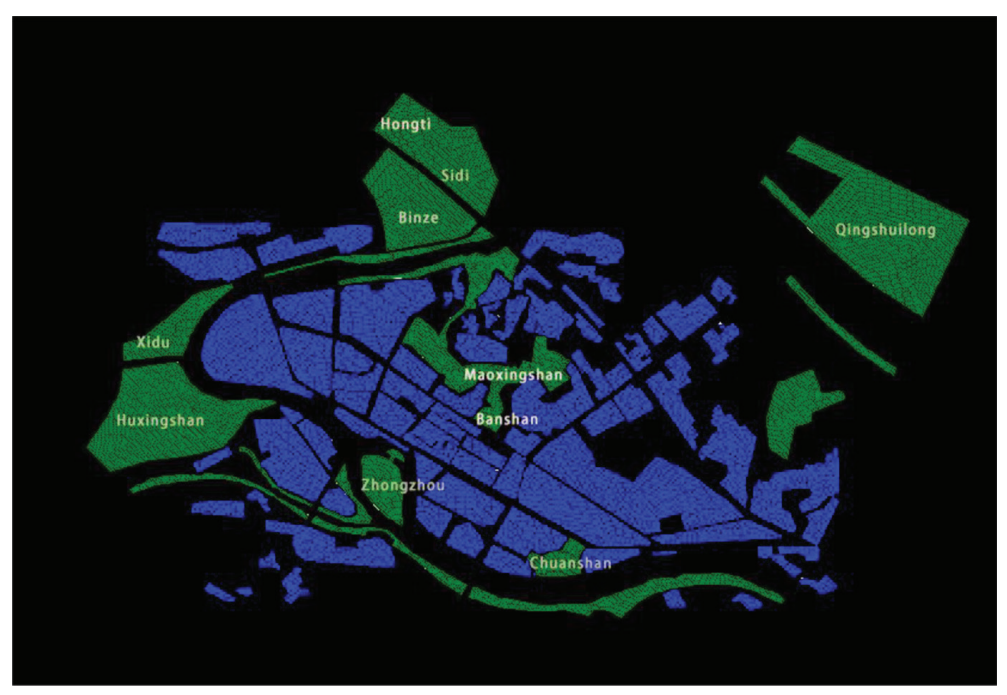

Figure 2: Simplified topographic map of Hengyang County. 
role in urban climate environment, so the main urban elements set in our study include green spaces, buildings, roads and impervious surfaces.

\subsubsection{Turbulence model}

It is generally believed that the unsteady state continuous equation and the Navier-Stokes equation are applicable to the instantaneous motion of turbulence. Here, considering the incompressible flow, using the Cartesian coordinate system. The basic governing equations of non-compressed, non-isothermal flow field are as follows:

1. Continuity Equation:

2. Momentum Equation:

$$
\frac{\partial \rho}{\partial t}+\operatorname{div}(\rho \mu)=0
$$

$$
\begin{gathered}
\frac{\partial(\rho \mu)}{\partial t}+\operatorname{div}(\rho \mu \vartheta)=-\frac{\partial \rho}{\partial x}+\frac{\partial \tau_{x x}}{\partial x}+\frac{\partial t_{y x}}{\partial z}+F_{x} \\
\frac{\partial(p v)}{\partial t}+\operatorname{div}(p v \vartheta)=\frac{\partial \rho}{\partial y}+\frac{\partial \tau_{x x}}{\partial x}+\frac{\partial t_{y y}}{\partial y}+\frac{\partial t_{z z}}{\partial z}+F_{y} \\
\frac{\partial(\rho w)}{\partial t}+\operatorname{div}(\rho w \bar{\vartheta})=-\frac{\partial \rho}{\partial z}+\frac{\partial \tau_{x z}}{\partial x}+\frac{\partial t_{y z}}{\partial y}+\frac{\partial t_{z z}}{\partial z}+F_{z}
\end{gathered}
$$

3. Energy Equation:

$$
\frac{\partial(\rho T)}{\partial t}+\frac{\partial(\rho u T)}{\partial x}+\frac{\partial(\rho v T)}{\partial y}+\frac{\partial(\rho w T)}{\partial z}+\frac{\partial}{\partial x}\left(\frac{k}{c_{p}} \frac{\partial T}{\partial x}\right)+\frac{\partial}{\partial y}\left(\frac{k}{c_{p}} \frac{\partial T}{\partial y}\right)+\left(\frac{k}{c_{p}} \frac{\partial T}{\partial z}\right)+S_{T}
$$

where: $\rho$ is the density of fluid $t$ is time; $\bar{v}$ is velocity vector; $p$ is pressure of a fluid microelement; $t_{x x}, t_{x y} t_{x z}$ are the components of the viscous stress $t$ on the surface of a microelement due to the adhesion of molecules; $c_{p}$ is specific heat capacity; $F_{x}, F_{y}, F_{z}$ are volume force on a microelement; $T$ is temperature; $k$ is heat transfer coefficient of fluid; $S_{T}$ is viscous dissipation term.

\subsubsection{Setting city boundary and initial conditions}

For the CFD model simulation, a large-scale three-dimensional urban geometric room was built, with a size of $4,920 * 2,467 * 400 \mathrm{~m}^{3}$. The initial setup condition variables of CFD model include wind speed, wind direction and temperature, etc. setting up both inlet and outlet in the corresponding position of the space, attached with relevant parameters (density, specific heat, thermal conductivity) and turbulence model. City average wind speed of $2.0 \mathrm{~m} / \mathrm{s}$ and the temperature of $295 \mathrm{~K}$ were based on data from the Hengyang Meteorological Station, and the northeast prevailing wind will be used. Considering the climate and environment characteristics of Hengyang County, that is, the spring and autumn are short; the summer and winter are long, and the south wind prevails in summer, so the south simulation is added in the planning scheme.

\subsubsection{Operation process}

The main models used in this study are turbulence model and energy conservation model. A semi implicit method of SIMPLE (pressure coupling equation) is used in the simulated 
temperature field. The pressure under - relaxation coefficient is 0.3 , and the momentum less relaxation coefficient is 0.7 . In the process of operation, it is necessary to adjust the parameters to promote the convergence of the model. In the current urban green space pattern, the iterative step reaches 2254 steps to achieve the desired simulation results after many times of parameter adjustment and simulation for more than 36 hours.

\section{RESULTS AND ANALYSIS}

\subsection{Ventilation paths delimitation}

Through the altitude, slope, aspect and model analysis of Hengyang County topography, Ventilation paths are segmented based on a combination of the following elements: urban space, mountain environment, buildings, water, and street directions (roughly along the south to east), vegetation coverage is high in the northeast of Hengyang County, green open space and Yuan River provide the best path for Urban Ventilation (Fig. 3).

\subsection{Urban climate environment simulation with green space layout}

The horizontal diffusion condition of wind speed at a height of $1.5 \mathrm{~m}$ is shown in Fig. 4 . Under the background of global warming, the typical urban climate is high temperature in summer, and the heat island effect is serious. Meanwhile, limited to the capacity of the computer and length of the article, this paper only studies the climate conditions under the typical climate conditions in Hengyang. In order to further study the pattern-effect mechanism, the simulation of the summer prevailing wind (south) winds is added.
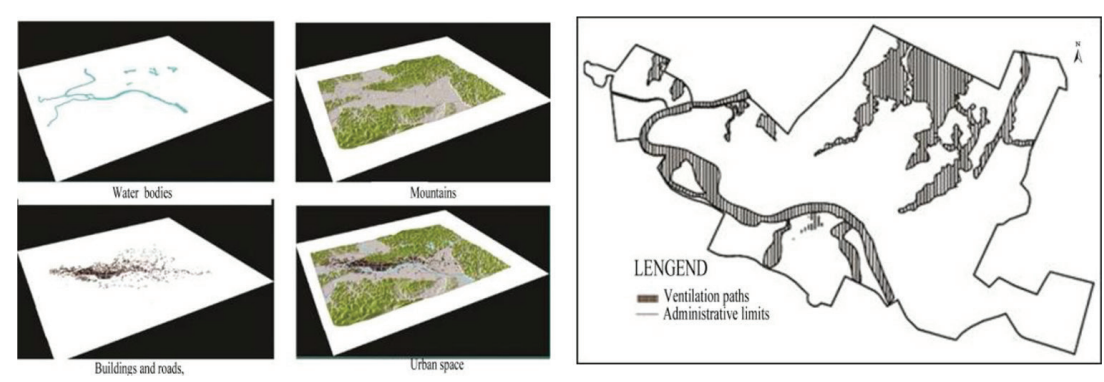

Figure 3: Urban ventilation paths.
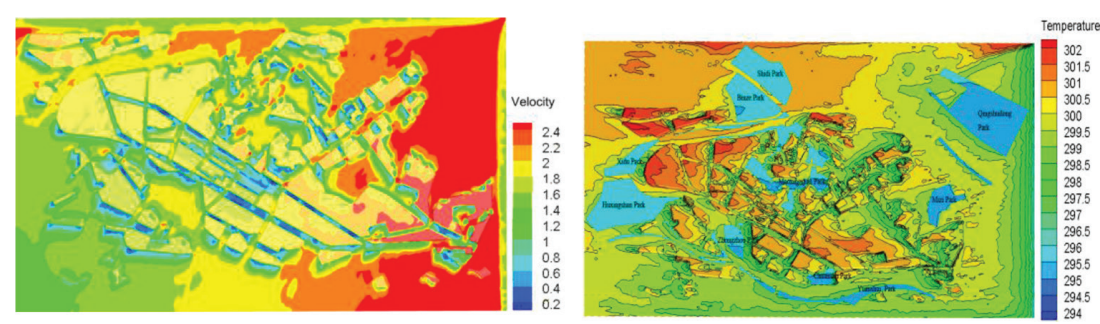

Figure 4: Plane analysis on the diffusion simulation of wind speed, land surface temperature under the influence of urban green space pattern in the northeast wind. 
3.2.1 The northeast wind simulation of the urban climate environment

It presents the wind and temperature horizontal dispersion at a height of $1.5 \mathrm{~m}$ above the ground. It indicates that the wind speed was fast in the main urban areas and the surrounding areas. The scope of low wind speed is less. The old west city temperature reached $2 \mathrm{~m} / \mathrm{s}$, Qingshuilong park, Mizi park, Chuanshan park form the main ventilation corridor in the city. The main road conforms to the dominant wind direction of the city, and combines with the green open space. It plays an important role in improving the urban wind environment and becomes the best area of urban ventilation, but on the lee side of the building, eddies were formed, and many low wind areas appeared. The influence extent of large green space on urban environment is related to distance, green space has obvious cooling effect for the surrounding area. The combination of wind and green space can take away most of the heat, alleviate urban heat island, improve the urban environment and air quality.

\subsubsection{The south wind simulation of the urban climate environment}

Figure 5 presents that the air flows out gradually until the suburbs, reflecting the continuous radiation characteristics of the wind environment. There is no obvious eddy current in Zhongzhou Park, Chuanshan square. The urban green space itself can be used as the ventilation corridor of the city, and strengthen the exchange of air. The relationship between the green space, the road and the dominant wind direction is very important. There is a low wind area in the more concentrated buildings in Hengyang county. Because of the large volume of buildings, there is no corresponding direction for the wind, but the wind speed increased considerably in the Mizi park, it shows the positive function of green open space to wind environment.

\subsubsection{Validation}

In order to quantitatively evaluate the reliability and applicability of the CFD simulation software, the simulated and measured values of the measured points are compared. In order to evaluate the accuracy of simulation, the root-mean-square error and the index of agreement were used to quantitatively evaluate the absolute and relative errors of the overall numerical simulation.

The calculation methods of RMSE and D values are as follows:

$$
R M S E=\sqrt{\frac{\sum_{i}^{N}\left(C_{i}-M_{i}\right)^{2}}{N}}
$$
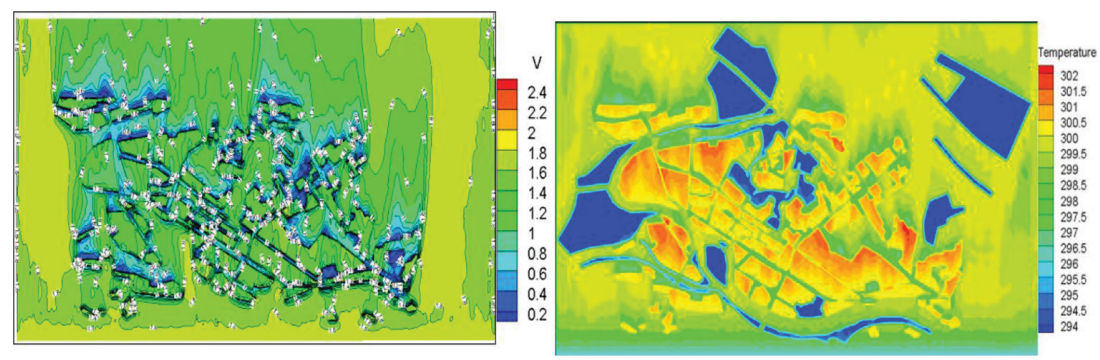

Figure 5: Plane analysis on the diffusion simulation of velocity and temperature under the influence of urban green space pattern in the south wind. 


$$
d=1-\frac{\sum_{i}^{N}\left(C_{i}-M_{i}\right)^{2}}{\sum_{i}^{N}\left(\left|C_{i}\right|+\left|M_{i}\right|\right)^{2}}, 0 \leq d \leq 1
$$

where: $C_{i}$ the simulated value and $M_{i}$ is the measured value.

Through the RMSE calculation, the error of $C_{i}$ and $M_{i}$ is $0.93^{\circ} \mathrm{C}$, and the $d$ is 0.92 . Therefore, the coupling relationship between $C_{i}$ and $M_{i}$ is good.

\subsection{Urban climate environment simulation without green space layout}

This part of the research is to set up scenario simulation, considering that the green space of the city will disappear in the process of rapid urbanization, it also compares the effect of urban climate environment on green land layout from another angle. The grid file used in this part is the planning green space layout model. The parameters of the green space are not set up, the green space is regarded as the lower surface of the concrete, and the other parameters remain the same as the planning layout patterns.

Through simulation studies (Fig. 6), it is found that under this layout model, The city wind environment has changed a lot, under the influence of the northeast wind of the dominant wind, the friction coefficient of the wind is relatively small because the underlying surface of the outer space is impervious to the surface, Moreover, the green space now exists as open space, so it has no great influence on the leading trend of the wind. But through the contours of the wind speed profile, wind speed changes faster in the green layout mode, the air stream forms a number of refraction changes mainly due to the roughness of the green pad surface, so the air flow is more active.

The urban green space has been changed into a city impervious to the surface. Because of its relatively high thermal radiation effect, it has a warming effect on the city. Due to the lack of the cooling effect of greening, the overall temperature area generally increased, and the temperature distribution of the whole city is relatively uniform, the highest temperature appears under the direction of the dominant wind. The eastern part of the city is warming up most obviously because of the lack of coupling between the green and the winds.

In summary, the green space of Hengyang county is very important in regulating the urban air environment and enhancing the urban climate adaptability, but it needs the wind to transfer its good ecological elements to the built-up area. Under the present circumstances, the urban air duct system is limited by the urban heat island effect and the urban dense construction, and the operation condition is poor. As a result, the green land has some moderating effect on the climate of Hengyang, but its potential is far from being fully realized. In particular, some unreasonable planning layout has hindered the air circulation in some parts of the
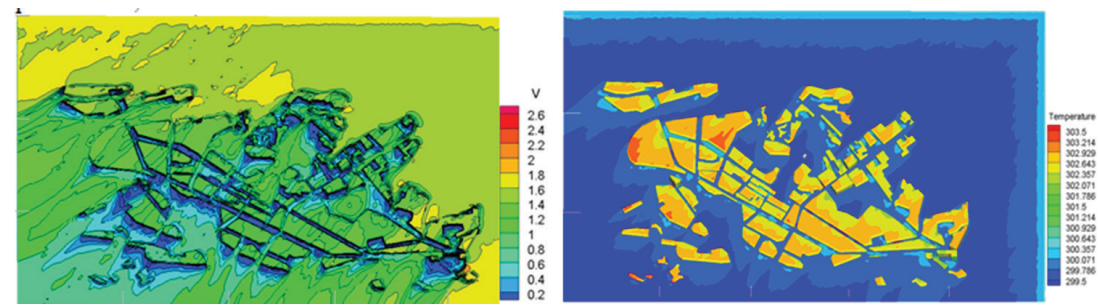

Figure 6: Plane analysis on the diffusion simulation of wind speed, land surface temperature without green land layout model. 
urban center, seriously damaged the wind environment, and made the green spaces ecological effects not accessible to these areas. Therefore, optimizing the urban spatial pattern is the necessary measure to improve the urban wind environment.

\subsection{Ventilation corridor design based on urban green space layout optimization}

The simulation research is based on the two models of the planning green space system and the no green space layout in Hengyang county to study the thermal environment effect of green space layout.

Based on simulation analysis of planning scheme, find the ventilation corridor is not very obvious, the thermal environment on both sides of the road is not significantly improved, ventilation corridor system has not been formed and the surrounding city thermal environment distribution is not uniform. The urban thermal environment in the central region is serious.

On this basis, this paper hopes to establish the reciprocal relationship between the Urban Ventilation Potential pattern and the urban green space layout, take the green space layout as the blueprint, based on the study of urban ventilation path, building a large green ventilation corridor that goes through urban built-up area interior, and communicates directly to the outskirts: scheme 1: 'ring green system' and scheme 2: 'Ring+band' (which contains one ring greenway + six belt greenways) (Fig. 7). Under the support of Urban Ventilation Theory, using CFD software to simulate and feedback, it provides a useful approach to the scientific guidance of urban planning and the demonstration of the thermal environment effect of green space.

\subsection{Urban climate environment simulation of optimization scheme}

As can be seen from the simulation results of scheme 1 (Fig. 8), the changes of the flow field in the urban thermal environment are in accordance with the simulation results of the green

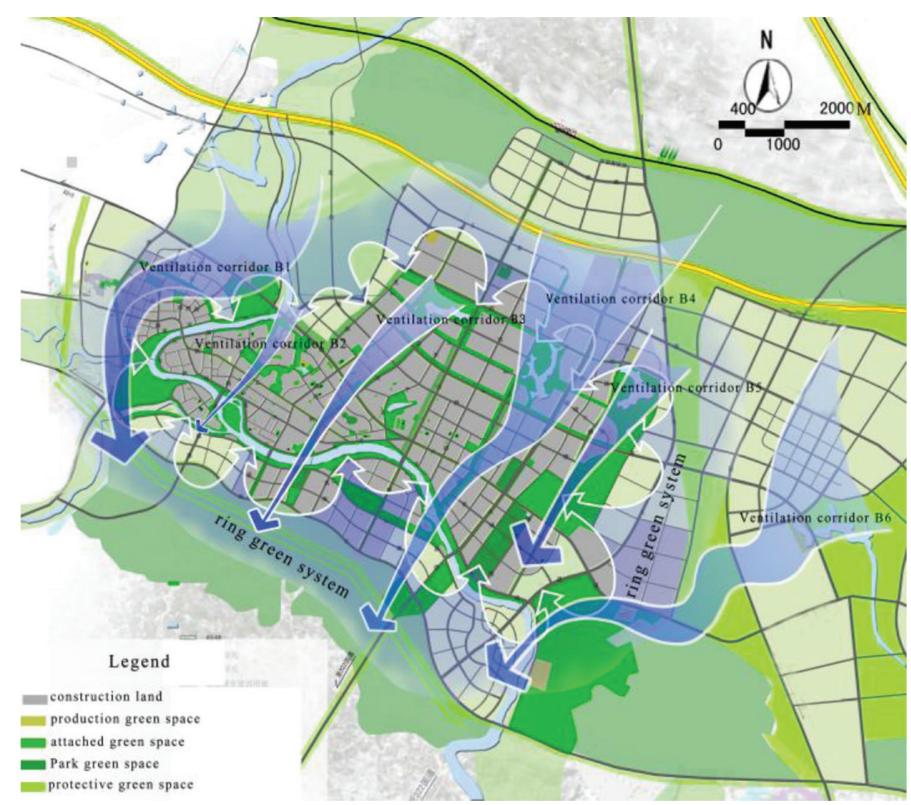

Figure 7: Ventilation corridor map of urban green space. 


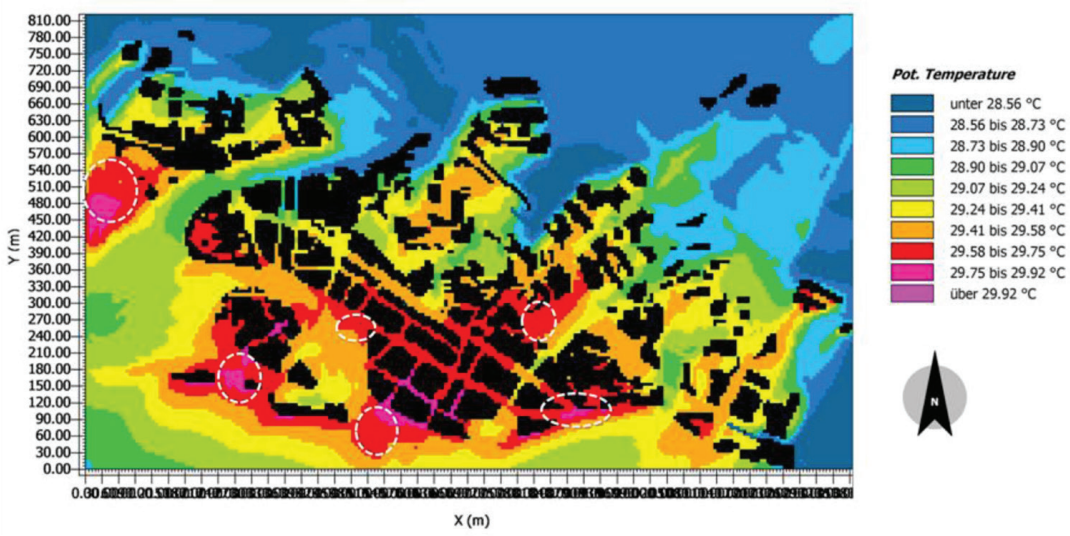

Figure 8: Temperature distribution map of ring green system.

space layout scheme, the thermal environment in the periphery is good, and the thermal environmental problems in the central area are serious. However, compared to the green space layout scheme above, due to the formation of the outer ring green space system, the thermal environment of the western part is obviously relieved. The main reason is that the macro ring green corridor ventilation connects Huxingshan park, Xidu old street park, and the Hongti park, the uneven distribution of temperature in the region has been improved, the thermal environment is good around the city, but there are also some high temperature zone, mainly concentrated in the area of Chuanshan square, the main reason is that the ventilation corridor in the old urban area has not been formed, which causes the heat not to be distributed. To the high-temperature zone, open the inner green corridor, constructing scheme 2 'The Ring+band' to further optimize simulation study.

By widening the ventilation corridors on both sides of the road, scheme 2 simulation clearly reflects the obvious improvement of the city's thermal environment (Fig. 9), the overall temperature declines by $0.53^{\circ} \mathrm{C}$, the thermal environment of Maoxingshan-

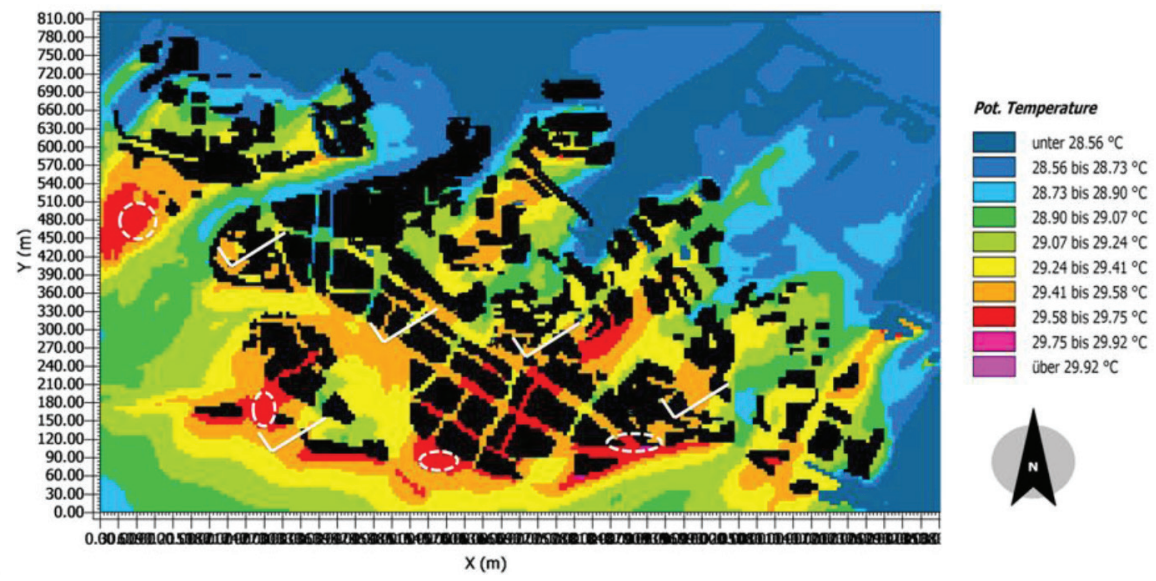

Figure 9: Temperature distribution map of ring+axis green system. 
Chuanshan square is good. The range of high temperature areas in the middle of the city is obviously narrowed. It can be seen that Hengyang County should continue to improve the urban green space planning structure and build a 'Ring+ band' structure of the green space network in the future, to ensure the ventilation corridors of the overall urban green space is open, in particular, communication corridors between the central area of the city and the large ecological green space in the suburbs, it will have an important role in the improvement of the thermal environment.

\section{CONCLUSION AND DISCUSSION}

Through the analysis above, we can see that the green space will effectively improve the urban ventilation and heat environment. The urban green space layout plays an important role in the relief of the thermal environment.

Based on the urban ventilation path and the optimization of urban green space layout, the 'Ring+band' ventilation corridor has continuously improved the thermal environment, which has been feedback verified by CFD.

Additionally, the limited simulation capacity of computer makes the research only working on those urban green patches that reach a certain scale, unfortunately ignoring the influence of urban micro green space. It can be also done on the basis of variety of influencing factors (i.e. PM2.5 and dispersion of air pollutants), in order to make a further guide of urban green space planning, and the existing limitations (smaller scale environmental simulations) of this study need to be resolved with the accumulation of related study experiences in the future.

\section{ACKNOWLEDGMENTS}

The authors give special thanks to the support by Hunan Provincial Natural Science Fund (2018JJ3171); the National Natural Science Fund (51478470); Subject of Hunan Social Science Achievement Assessment Committee (XSP19YBC018).

\section{REFERENCES}

[1] Alcoforado, M.J., Andrade, H., Lopes, A. \& João, V., Application of climatic guidelines to urban planning: the example of Lisbon(Portugal). Landscape and Urban Planning, 90(1-2), pp. 56-65, 2009. (In English). https://doi.org/10.1016/j.landurbplan.2008.10.006

[2] Barbosa, O., Tratalos, J.A., Armsworth, P.R., Richard, G.D., Richard, A.F., Pat, J. \& Kevin, J.G., Who benefits from access to green space? A Case Study from Sheffield.UK.Landscape and Urban Planning, 83(2-3), pp. 187-195, 2007. (In English). https://doi.org/10.1016/j.landurbplan.2007.04.004

[3] Feng, X.-H., Study of the environmental effects of urban green space and wind. Chinese Landscape Architecture, 26(2), pp. 82-84, 2010. (In Chinese).

[4] Wong, M.S., Nichol, J.E., To, P.H. \& Jingzhi W., A simple method for designation of urban ventilation corridors and its application to urban heat island analysis. Building and Environment, 45(8), pp. 1880-1889, 2010. (In English). https://doi.org/10.1016/j. buildenv.2010.02.019

[5] Miao, S., Xiaoyun, W., Weimei, J. \& Wenli, G., Impact on atmospheric environment by green space layout in urban planning: a case study on green space planning of Chengdu urban planning, 37(6), pp. 42-45, 2013. (In Chinese). 
[6] Zhou, X.L. \& Wang, Y.C., Spatial-temporal dynamics of urban green space in response to rapid urbanization and greening policies. Landscape and Urban Planning, 100(3), pp. 268-277, 2011. (In English).

[7] Huang, H., Ooka, R., Chen, H., Kato, S., Takahashi, T. \& Watanabe, T., CFD analysis on traffic-induced air pollutant dispersion under non-isothermal condition in a complex urban area in winter. Journal of Wind Engineering and Industrial Aerodynamics, 96(10-11), pp. 1774-1788, 2008. (In English). https://doi.org/10.1016/j.jweia.2008.02.010

[8] Akbari, H., Pomerantz, M. \& Taha, H., Cool surfaces and shade trees to reduce energy use and improve air quality in urban areas. Solar Energy, 70(3), pp. 295-310, 2001. (In English). https://doi.org/10.1016/s0038-092x(00)00089-x 